\title{
Eiszeitalter - Kalt-/Warmzeit-Zyklen und Eistransport im alpinen und voralpinen Raum
}

\author{
Samuel Wyder \\ Eggenbergstrasse 12, 8127 Forch, Swizterland \\ Correspondence to: Samuel Wyder (ewyder@bluewin.ch)
}

Published: 18 March 2016

Hantke, R.: Eiszeitalter - Kalt-/Warmzeit-Zyklen und Eistransport im alpinen und voralpinen Raum, Ott Verlag, Bern, 576 S., ISBN-13: 978-3-7225-0121-5, EUR 63, 2011.

1978 erschien der erste Band und 1983 und 1988 folgten zwei weitere Bände des „Eiszeitalters“. Seither haben sich die Untersuchungsmethoden rasant entwickelt, und viele neue Erkenntnisse haben unser Wissen bereichert. Neue Publikationen haben in allen Gebieten spannende Einblicke in den Wechsel von Warm- und Kaltzeiten gegeben, die unser Verständnis erleichtern. Es war deshalb sinnvoll, die Ereignisse welche die Alpen und weite Gebiete des Vorlands geprägt haben, neu zu beschreiben. Das neue Buch fasst das ganze heutige Wissen in knapper und klarer Sprache zusammen. Es ist übersichtlich gegliedert und erscheint in einem modernen Layout.

Die ersten vier Abschnitte beschreiben den zeitlichen Ablauf der verschiedenen Kalt- und Warmzeiten von den ersten Anzeichen einer Vergletscherung an der Oligozän/Miozän Grenze bis zu den grossen pleistozänen Kaltzeiten. Der Autor vertritt die Ansicht, dass Eisströme in die in Entstehung begriffenen Täler flossen und die Talflanken längs von Klüften durch Frostsprengung erweitert wurden. Eine Erosion durch die Gletscher, welche die Täler vertieft hätten, fand kaum statt. Hangschutt und Ablagerungen der Schmelzwässer füllten die tektonisch bedingten Übertiefungen auf, und bei einem späteren Gletschervorstoss floss das Eis über diese Ablagerungen.
Im Hauptteil des Buches werden die einzelnen Gletschersysteme abgehandelt, vom Ursprung in den Karen bis zu den Ablagerungen in Moränen und in Schottern der Schmelzwässer. Der Autor beschreibt nacheinander die grossen Eisströme des Alpengebiets vom Rhone Gletscher bis zum Dora Balteo Gletscher in ähnlicher Weise wie bei den Vorgängerbänden. Er ergänzt und erweitert seine früheren Ausführungen durch die seither neu gewonnenen Erkenntnisse, wobei er stets zeigt, welche Autoren zu dieser Erweiterung unseres Wissens beigetragen haben. Jedes Kapitel wird durch ein Verzeichnis der heute vorhandenen Literatur abgeschlossen. Wer sich in ein bestimmtes Gebiet vertiefen will, findet mühelos die nötige Fachliteratur nachgeführt bis 2011. Ein ausführliches Sachregister sowie ein Ortsregister erleichtern die Arbeit der Benutzer. 